\title{
Chemical characterization and bioactivity of phytochemicals from Iberian endemic Santolina semidentata and strategies for ex situ propagation
}

\author{
Andreia Gomes $^{\mathrm{a}, \mathrm{b}}$, Rui C. Pimpão ${ }^{\mathrm{a}}$, Sofia Fortalezas ${ }^{\mathrm{a}, \mathrm{b}}$, Inês Figueira ${ }^{\mathrm{a}}$, Célia Miguel ${ }^{\mathrm{a}, \mathrm{b}}$, \\ Carlos Aguiar ${ }^{\mathrm{c}}$, Lígia Salgueiro ${ }^{\mathrm{d}}$, Carlos Cavaleiro ${ }^{\mathrm{d}}$, Maria José Gonçalves ${ }^{\mathrm{d}}$, \\ Adelaide Clemente ${ }^{\mathrm{e}}$, Catarina Costa $^{\mathrm{e}}$, Maria Amélia Martins-Loução ${ }^{\mathrm{e}}$, \\ Ricardo B. Ferreira ${ }^{\mathrm{a}, \mathrm{f}}$, Cláudia N. Santos ${ }^{\mathrm{a}, \mathrm{b}, *}$ \\ a Instituto de Tecnologia Química e Biológica António Xavier, Universidade Nova de Lisboa, Av. da República, 2780-157 Oeiras, Portugal \\ b Instituto de Biologia Experimental e Tecnológica, Apartado 12, 2781-901 Oeiras, Portugal \\ c Centro de Investigação de Montanha, Instituto Politécnico de Bragança, Apartado 1172, Bragança 5301-855, Portugal \\ d Faculdade de Farmácia/CEF e CNC, Pólo das Ciências da Saúde, Azinhaga de Santa Comba, Universidade de Coimbra, 3000-548 Coimbra, Portugal \\ e Jardim Botânico, Museu Nacional de História Natural and CE3C - Centre for Ecology, Evolution and Environmental Changes, Faculdade de Ciências, \\ Universidade de Lisboa, Campo Grande, 1749-016 Lisboa, Portugal \\ ${ }^{\mathrm{f}}$ Departamento de Botânica e Engenharia Biológica, Instituto Superior de Agronomia, Universidade Técnica de Lisboa, Tapada da Ajuda, 1349-017 Lisboa, \\ Portugal
}

\section{A R T I C L E I N F O}

\section{Article history:}

Received 3 January 2015

Accepted 17 April 2015

Available online 12 June 2015

\section{Keywords:}

Santolina semidentata

Iberian endemism

Phytomolecules

Essential oil

Neuroprotection

Acetylcholinesterase inhibitor

Propagation protocol

Polyphenol

\begin{abstract}
A B S T R A C T
Asteraceae family members are well-known for their medicinal potential, comprising several properties that make them unique among plants. Here we focus on Santolina semidentata, an endemic plant from the Iberian Peninsula, not yet described for its medicinal properties. Phytochemical characterization of S. semidentata was performed, concerning total phenol content, flavonoid content, antioxidant capacity, HPLC-DAD profile, acetylcholinesterase inhibitory capacity, cytotoxicity and neuroprotective effect in a human neurodegeneration cell model. Moreover, essential oil composition and antifungal activity were also analised. This oil might be useful for therapeutical purposes, particularly in the treatment of dermatophytosis. S. semidentata potential for neuroprotection was revealed by acetylcholinesterase inhibitory capacity and also by an effective protective effect in human neuronal cells. Furthermore, different seed conservation protocols, as well as successful in vitro propagation were established which may be useful when integrated in a broad strategy for the conservation of these endemic plants and their sustainable use for potential biotechnological applications. The results presented here greatly contribute to value this species regarding its potential as a source of phytochemicals with prospective neuroprotective health benefits, either as alternative neuroprotective drugs or as leads for synthetizing more effective molecules.
\end{abstract}

(C) 2015 Elsevier B.V. All rights reserved.

\section{Introduction}

From very early times, medicinal plants have been a rich source of biologically active compounds. Asteraceae (Compositae) species have been largely used in traditional medicine, being currently studied for their antioxidant, antimicrobial, antiviral, anti-inflammatory, anti-Alzheimer's disease and free radical scavenging potential (Ardestani and Yazdanparast 2007; De Logu et al.,

\footnotetext{
* Corresponding author. Tel.: +351 214469651; fax: +351 214433644.

E-mail address: csantos@itqb.unl.pt (C.N. Santos).
}

2000; Fabri et al., 2011; Naqash and Nazeer 2011; Nikolova et al., 2011; Shahwar et al., 2011; Tavares et al., 2011). Plants from this family have been described as important sources of flavonoids, terpenoids and coumarins, responsible for antimicrobial, antioxidant and hepatoprotective activities (Fabri et al., 2011; Casado et al., 2002; Sacchetti et al., 1997; Silván et al., 1996; Utrilla et al., 1995). Within the Asteraceae family, Santolina spp. have already been used as source of several natural products including flavonoids, terpenoids, coumarins and polyacetylenes, evidencing the medicinal interest of these plants (Ferrari et al., 2005; Casado et al., 2002; Sacchetti et al., 1997; Silván et al., 1996; Utrilla et al., 1995). 
Due to these unique potential properties to be used in medicine, chemical characterization of Santolina species is relevant. The genus Santolina is represented by more than 100 species widely distributed in the Mediterranean area (Ferrari et al., 2005). Santolina semidentata Hoffmanns. \& Link is an endemic plant of the northwestern Iberian Peninsula (León, south of Lugo, northeastern portion of Ourense, north of Zamora and Trás-os-Montes provinces, and the Brezo massif) (Rivero-Guerra, 2009) and its extent of occurrence in Portugal and Spain spans along $3,904 \mathrm{~km}^{2}$ (CEC, 2009). S. semidentata is found at altitudes of $400-1400 \mathrm{~m}$ above sea level, usually on slates and quartzite or schist (Rivero-Guerra, 2009). It is a relatively common species, being present in 36 localities in Spain and has been estimated to have 10,000 individuals in Portugal (CEC, 2009; ICN, 2006).

There is no reported information for potential bioactive compounds from $S$. semidentata plants. Therefore, the evaluation of chemical profiling can reveal possible future applications of this species, not yet extensively characterized. To address the potential of plants from S. semidentata as sources of bioactive products, phytochemical evaluation was performed through spectrophotometric and chromatographic methods: total phenol content, flavonoid content, HPLC-DAD profile of extracts and essential oil composition. Also antioxidant capacity, cytotoxicity profile, neuroprotective effect and acetylcholinesterase inhibitory capacity of extracts, as well as antifungal activity of the essential oils were evaluated. Moreover, the establishment of successful seed conservation, in vitro germination and vegetative propagation represents a potentially useful approach towards species conservation and sustainable use. Micropropagation protocols able to induce multiplication of plants while maintaining the production of bioactive compounds have been reported for other Santolina species (Casado et al., 2002; Iglesias et al., 2000) but not for S. semidentata. In this work, we report an efficient procedure for in vitro micropropagation of $S$. semidentata from seedlings up to the rooting and acclimatization steps.

\section{Material and methods}

\subsection{Plant material}

S. semidentata life specimens were collected from their wild habitat, in Bragança region (herbarium voucher number 7945 and 7496 from BRESA-Herbário da Escola Superior Agrária de Bragança, Portugal). Samples of plant material, namely leaves and stalks, were mashed and freeze-dried until analysis. For essential oil isolation dried leaves were used.

\subsection{Extraction of plant phytomolecules}

The extraction of plant phytomolecules from leaves and stalks was performed as described earlier (Fortalezas et al., 2010; Tavares et al., 2010a,b). Briefly, to each gram of lyophilized powder, $12 \mathrm{~mL}$ of hydroethanolic solvent ( $50 \%(\mathrm{v} / \mathrm{v})$ ethanol/water) was added, and the mixture was shaken for $30 \mathrm{~min}$ at room temperature in the dark. The mixture was then centrifuged at $12,400 \times g$ for $10 \mathrm{~min}$ at room temperature. The supernatant was filtered through filter paper and then through $0.2 \mu \mathrm{m}$ cellulose acetate membrane filters. The resulting hydroethanolic extracts were fractionated by solid phase extraction (SPE) using a Giga tubes $2 \mathrm{~g} / 12 \mathrm{~mL}$, C18E units (Phenomenex ${ }^{\circledR}$ ) as described before in order to obtain a (poly)phenol-enriched fraction (PEF) (Tavares et al., 2010a,b).

\subsection{Total phenolic and total flavonoid content}

Determination of total phenolic compounds was performed by the Folin-Ciocalteau method adapted to microplate reader as described in previous work (Fortalezas et al., 2010). Gallic acid was used as standard and results are expressed in $\mathrm{mg}$ of gallic acid equivalents per gram of dry weight ( $\mathrm{mg} \mathrm{GAE} \mathrm{g}^{-1} \mathrm{dw}$ ) of plant material. Measurement of total flavonoid content was performed by a modification of the $\mathrm{AlCl}_{3}$ complexation method as described before (Tavares et al., 2010a,b).

\subsection{HPLC profile}

HPLC analysis of S. semidentata PEF was performed as described earlier (Hitachi HPLC instrument (VWR) equipped with EZChrom Elite software (Agilent), Inertsil ODS-3 V column) (Gomes et al., 2013).

\subsection{Essential oils isolation and analysis}

The essential oils were isolated by hydrodistillation for $3 \mathrm{~h}$ using a Clevenger-type apparatus according to the procedure described in the European Pharmacopoeia (Council of Europe, 1997). Analyses of the oils were carried out by both gas chromatography (GC) and gas chromatography/mass spectrometry (GC/MS), using fused silica capillary columns with two different stationary phases (SPB-1 and SupelcoWax-10) as previously reported (Cavaleiro et al., 2004). The volatile compounds were identified by both their retention indices and their mass spectra. Retention indices, calculated by linear interpolation relative to retention times of a series of $n$-alkanes, were compared with those of authenticated samples from the database of the Laboratory of Pharmacognosy, Faculty of Pharmacy, University of Coimbra. Mass spectra were compared with reference spectra from a home-made library or from literature data (Adams 1995; Joulain and König, 1998). Relative amounts of individual components were calculated based on GC peak areas without FID response factor correction.

\subsection{Antioxidant capacity}

Antioxidant capacity of plant hydroethanolic extracts and PEF was determined by the oxygen radical absorbance capacity (ORAC) method adapted to microplate as described earlier (Fortalezas et al., 2010). Trolox was used as standard and results are expressed in $\mu \mathrm{mol}$ of trolox equivalents per gram of plant dry weight ( $\mu \mathrm{mol}$ $\left.\mathrm{TE} \mathrm{g}^{-1} \mathrm{dw}\right)$.

\subsection{Acetylcholinesterase (AChE) inhibitory assay}

AChE inhibition of $S$. semidentata hydroethanolic extract and PEF was determined in a ninety six microtiter well plate, based on Ellman's reaction (Ellman et al., 1961), according with (Tavares et al., 2011). Effect on AChE activity was calculated as an inhibition percentage (\%) of the maximum activity (registered on control wells without inhibitor). Physostigmine was used in the assay as positive control. Results were transformed using a nonlinear regression with Origin Pro 6.1 software (OriginLab ${ }^{\circledR}$, USA) and the IC50 values were determined.

\subsection{Cytotoxicity profile}

PEF of S. semidentata was concentrated under vacuum and dissolved in cell medium for the cytotoxicity tests (Fortalezas et al., 2010; Gomes et al., 2013; Tavares et al., 2012a,b). The cell viability assay was performed in a 96 well plate cell with a neuroblastoma human cell line SK-N-MC. Cells were seeded at $1.25 \times 10^{5}$ cells $\mathrm{mL}^{-1}$ and grown for $24 \mathrm{~h}$ prior to incubation with extracts. Toxicity tests involved $24 \mathrm{~h}$ incubation in the range $0-200 \mu \mathrm{g} \mathrm{GAE} \mathrm{mL}^{-1}$ of medium. Cell viability was assessed using the CellTiter-Blue ${ }^{\circledR}$ Cell Viability Assay (Promega), according to 
the manufacturer's instructions. Non-viable cells rapidly lose their metabolic capacity and thus do not generate the fluorescent signal.

\subsection{Neuroprotective effect against oxidative stress}

To evaluate the neuroprotective effect of extracts, SK-N-MC neuroblastoma cells were incubated in the presence of $\mathrm{H}_{2} \mathrm{O}_{2}$ (Gomes et al., 2013; Tavares et al., 2012a,b). Briefly, cells were seeded at $7.4 \times 10^{4}$ cells $\mathrm{mL}^{-1}$ and, $24 \mathrm{~h}$ after seeding, growth medium was removed and wells were washed with PBS. Cells were preincubated with non-toxic concentrations of $S$. semidentata extracts. After $24 \mathrm{~h}$ of pre-incubation, cells were washed again with PBS and medium with $\mathrm{H}_{2} \mathrm{O}_{2}$ at a final concentration of $300 \mu \mathrm{M}$ was added. After $24 \mathrm{~h}$, neuroprotective potential viability was assessed using the CellTiter-Blue ${ }^{\circledR}$ Cell Viability Assay (Promega).

\subsection{Antifungal activity of the essential oil}

Antifungal activity of the sample was evaluated against yeasts, Aspergillus and dermatophyte strains: two clinical Candida strains isolated from recurrent cases of vulvovaginal and oral candidosis (Candida krusei H9 and Candida guillermondii MAT23); three Candida type strains from the American Type Culture Collection (Candida albicans ATCC 10231, Candida tropicali sATCC 13803, and Candida parapsilopsis ATCC 90018); one Cryptococcus neoformans type strain from the Colección Espanõla de Cultivos Tipo (Cryptococcus neoformans CECT 1078); one Aspergillus clinical strain isolated from bronchial secretions (Aspergillus flavus F44) and two Aspergillus type strains from the American Type Culture Collection (Aspergillus niger ATCC 16404 and Aspergillus fumigatus ATCC 46645); three dermatophyte clinical strains isolated from nails and skin (Epidermophyton floccosum FF9, Microsporum canis FF1, and Trichophyton mentagrophytes FF7), and four dermatophyte type strains from the Colección Espanõla de Cultivos Tipo (Microsporum gypseum CECT 2908, Trichophyton mentagrophytes var. interdigitale CECT 2958, Thrichophyton rubrum CECT 2794, Trichophyton verrucosum CECT 2992).

A macrodilution broth method was used to determine the minimal inhibitory concentrations (MIC) and minimal lethal concentrations (MLC) of the oil according to the clinical and laboratory standards institute (CLSI) reference protocols M27-A3 (CLSI, 2008a) and M38-A2 (CLSI, 2008b) for yeasts and filamentous fungi, respectively, as previously reported (Vale-Silva et al., 2010).

\subsection{Seed conservation and in vitro propagation}

Seeds of $S$. semidentata were collected from wild plants growing in Bragança region and sent to the Seed Bank A.L. Belo Correia, Museu Nacional de História Natural e da Ciência and to Seed Bank Prof. João do Amaral Franco, Jardim Botânico da Ajuda Instituto Superior de Agronomia. Seeds were dried at 15\% relative humidity at $15^{\circ} \mathrm{C}$, and stored at $-18^{\circ} \mathrm{C}$ (ENSCONET, 2009; FAO/IPGRI, 1994) at the Seed Bank A.L. Belo Correia, Museu Nacional de História Natural e da Ciência. Germination of S. semidentata was compared under different temperature regimes $-15^{\circ} \mathrm{C}, 20^{\circ} \mathrm{C}$ and $25^{\circ} \mathrm{C}$ constant temperatures and an alternate temperature,
$20 / 10^{\circ} \mathrm{C}$ (day/night) -in order to identify optimum germination conditions to monitor the viability of banked seeds at the Seed Bank A.L. Belo Correia (ENSCONET, 2009). For each temperature regime, four replicates of 25 seeds were sown on filter paper in $9 \mathrm{~cm}$ diameter Petri dishes, and placed in germination incubators (Fitoclima S600, Aralab, Lisboa) with a $16 / 8 \mathrm{~h}$ photoperiod and white fluorescent light $\left(44 \mu \mathrm{mol} \mathrm{m}^{-2} \mathrm{~s}^{-1}\right)$. Germination was recorded over 55 days. Radicle emergence (approximately $1 \mathrm{~mm}$ ) was the criterion used for scoring a seed as germinated. At the end of the incubation period, ungerminated seeds were classified as mouldy, empty or firm and full through a cut test and germination percentage was calculated.

\subsubsection{Disinfection of seeds}

Seeds of S. semidentata collected from wild plants growing in Bragança region were surface-sterilized by a brief immersion in $70 \%(\mathrm{v} / \mathrm{v})$ ethanol and then disinfected in $1 \%(\mathrm{v} / \mathrm{v}), 2 \%(\mathrm{v} / \mathrm{v})$, or $3 \%$ $(\mathrm{v} / \mathrm{v})$ sodium hypochlorite $(\mathrm{NaClO})$ with $0.1 \%(\mathrm{v} / \mathrm{v})$ Tween-20 for 5 or $10 \mathrm{~min}$. After rinsing five times with sterile distilled water, seeds were germinated aseptically in Petri dishes containing halfstrength MS medium (Murashige and Skoog, 1962) with 2\% (w/v) sucrose and $0.7 \%(\mathrm{w} / \mathrm{v})$ agar, $\mathrm{pH}$ 5.7. Cultures were maintained for 4 days at $4{ }^{\circ} \mathrm{C}$ in the dark and afterwards transferred to a growth chamber at $22 \pm 2{ }^{\circ} \mathrm{C}$ or $15 \pm 2{ }^{\circ} \mathrm{C}$ both with a $16 \mathrm{~h}$ photoperiod, with white fluorescent light $\left(35 \mu \mathrm{mol} \mathrm{m} \mathrm{m}^{-2} \mathrm{~s}^{-1}\right)$. The percentages of germination were recorded for 30 days.

\subsubsection{Multiplication of seedling-derived shoots}

Apical shoots were removed from the seedlings and placed on MS medium supplemented with $3 \%(\mathrm{w} / \mathrm{v})$ sucrose and $0.7 \%(\mathrm{w} / \mathrm{v})$ agar, (pH 5.7) and without growth regulators, and maintained in a growth chamber at $22 \pm 2{ }^{\circ} \mathrm{C}$ and a $16 \mathrm{~h}$ photoperiod, with white fluorescent light ( $35 \mu \mathrm{mol} \mathrm{m}^{-2} \mathrm{~s}^{-1}$ ). Multiplication rate (calculated as the ratio of shoot number at the end of the subculture minus the initial number of shoots to the initial number of shoots) was recorded after each subculture.

\subsubsection{Adventitious rooting and acclimatization}

For root induction, shoots were transferred to MS medium with $2 \%(\mathrm{w} / \mathrm{v})$ sucrose and $0.7 \%(\mathrm{w} / \mathrm{v})$ agar without growth regulators, and maintained at least 2 weeks in these conditions. A $16 \mathrm{~h}$ immersion of basal ends in a solution of indole-3-butyric acid (IBA) at $183 \mathrm{mg} \mathrm{L}^{-1}$ ( $\mathrm{pH} 5.8$ ), solidified with $0.2 \%$ agar followed by transfer to MS media without growth regulators containing $2 \%(\mathrm{w} / \mathrm{v})$ sucrose and $0.7 \%(\mathrm{w} / \mathrm{v})$ agar for 7 days, was also tested (Tereso et al., 2008). Rooting success was expressed in terms of rooting frequency, root number, and the longest root length per plantlet. Rooted shoots were transplanted into plastic pots containing a mixture of soil, peat and perlite $(1: 1: 1, \mathrm{v} / \mathrm{v})$ or commercial substrate PINDSTRUP Universal, at $22 \pm 2{ }^{\circ} \mathrm{C}$ and $16 \mathrm{~h}$ light photoperiod under $35 \mu \mathrm{mol} \mathrm{m}^{-2} \mathrm{~s}^{-1}$ light intensity. Relative humidity was decreased over time by gradually opening the plastic that initially covered the pots.

Table 1

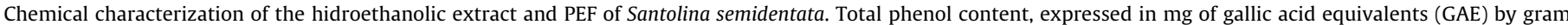

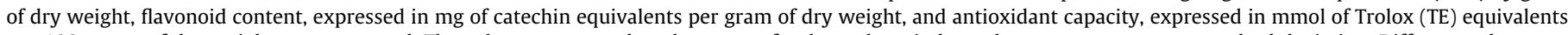

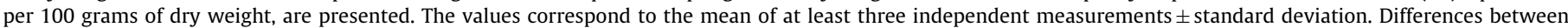
hydroethanolic extract and PEF are denoted as ${ }^{* * *} p<0.001$.

\begin{tabular}{|c|c|c|}
\hline & Hydroethanolic extract & PEF \\
\hline Total phenol content (mg GAE g $\left.{ }^{-1} \mathrm{dw}\right)$ & $23.16 \pm 0.49$ & $34.04 \pm 0.86^{* * *}$ \\
\hline Total flavonoid content ( $\left.\mathrm{mg} \mathrm{CE} \mathrm{g}^{-1} \mathrm{dw}\right)$ & $11.86 \pm 0.12$ & $28.55 \pm 1.06^{* * *}$ \\
\hline Antioxidant capacity (mmol TE $100 \mathrm{~g}^{-1} \mathrm{dw}$ ) & $58.96 \pm 3.94$ & $81.95 \pm 1.24^{* * *}$ \\
\hline
\end{tabular}




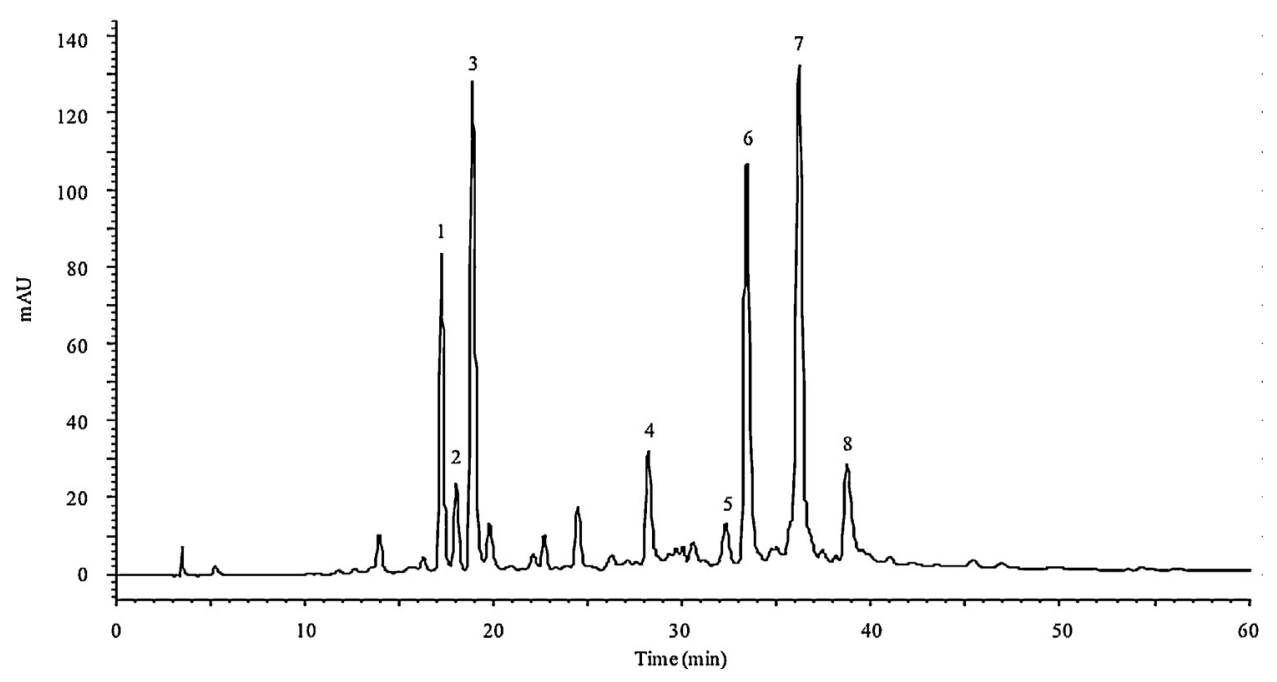

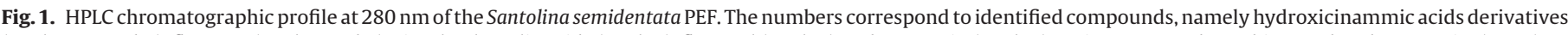
(peaks 3, 7 and 8), flavones (peak 4 and 6), simple phenolic acids (peak 1), flavonol (peak 5) and coumarin (peak 2). Units expressed as arbitrary absorbance units (mAU).

\subsection{Statistical analysis}

The results reported in this work are the averages of at least three independent experiments and are represented as the mean \pm SD. Differences among treatments were detected by analysis of variance with Tukey HSD (Honestly Significant Difference) multiple comparison test $(\alpha=0.05)$. All statistical analyses were performed using SigmaStat 3.10 (Systat) software (Systat software
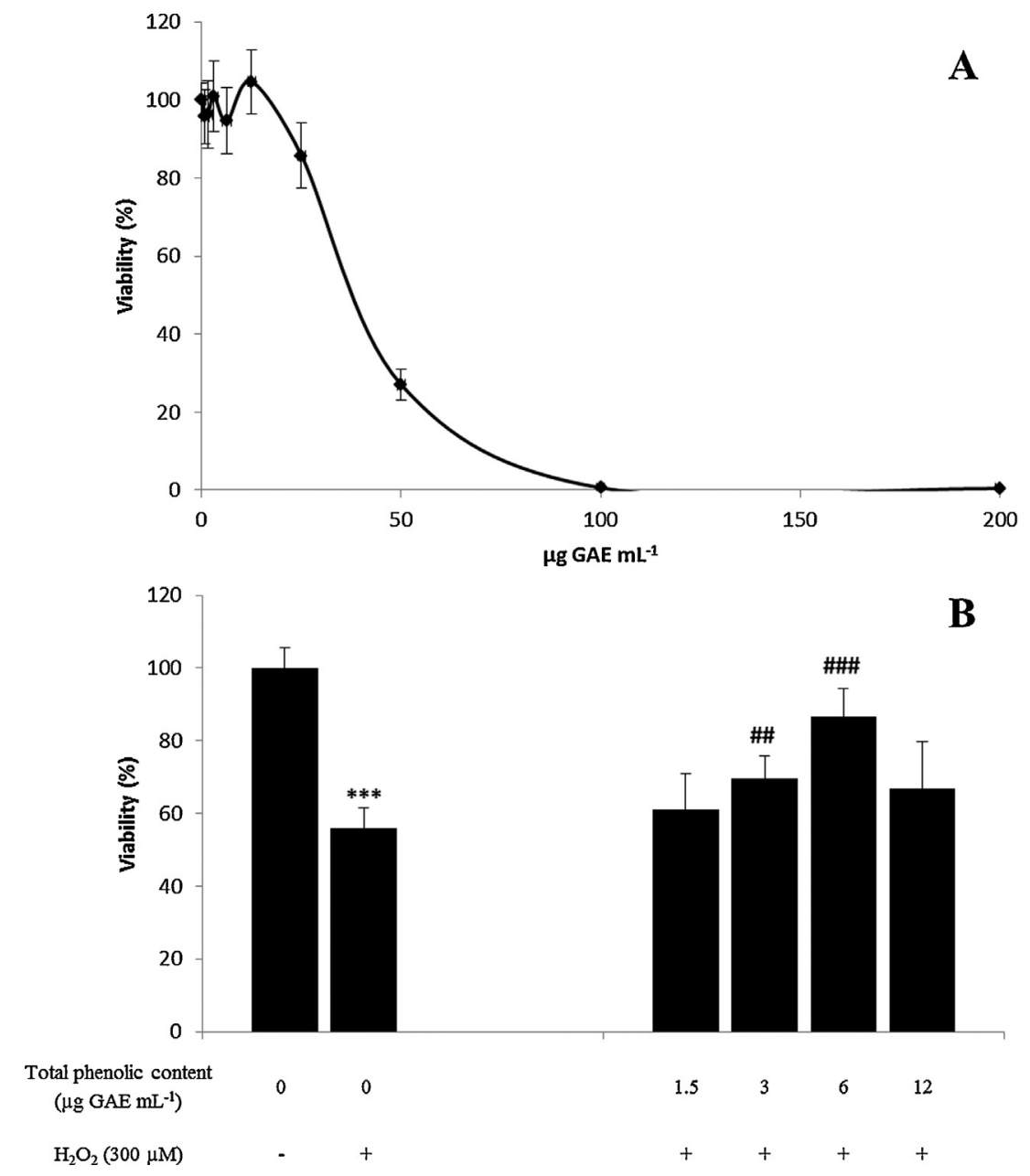

B

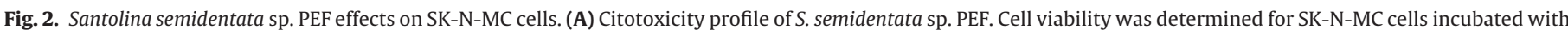

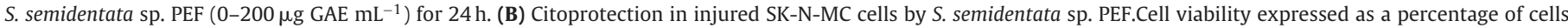

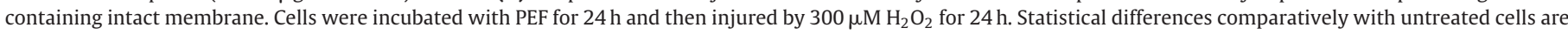
denoted as ${ }^{* * *} p<0.001$; statistical differences comparatively with injured cells are denoted as \#\#p $<0.01$, \#\#\#p<0.001. All values are mean \pm SD, $n=6$. 

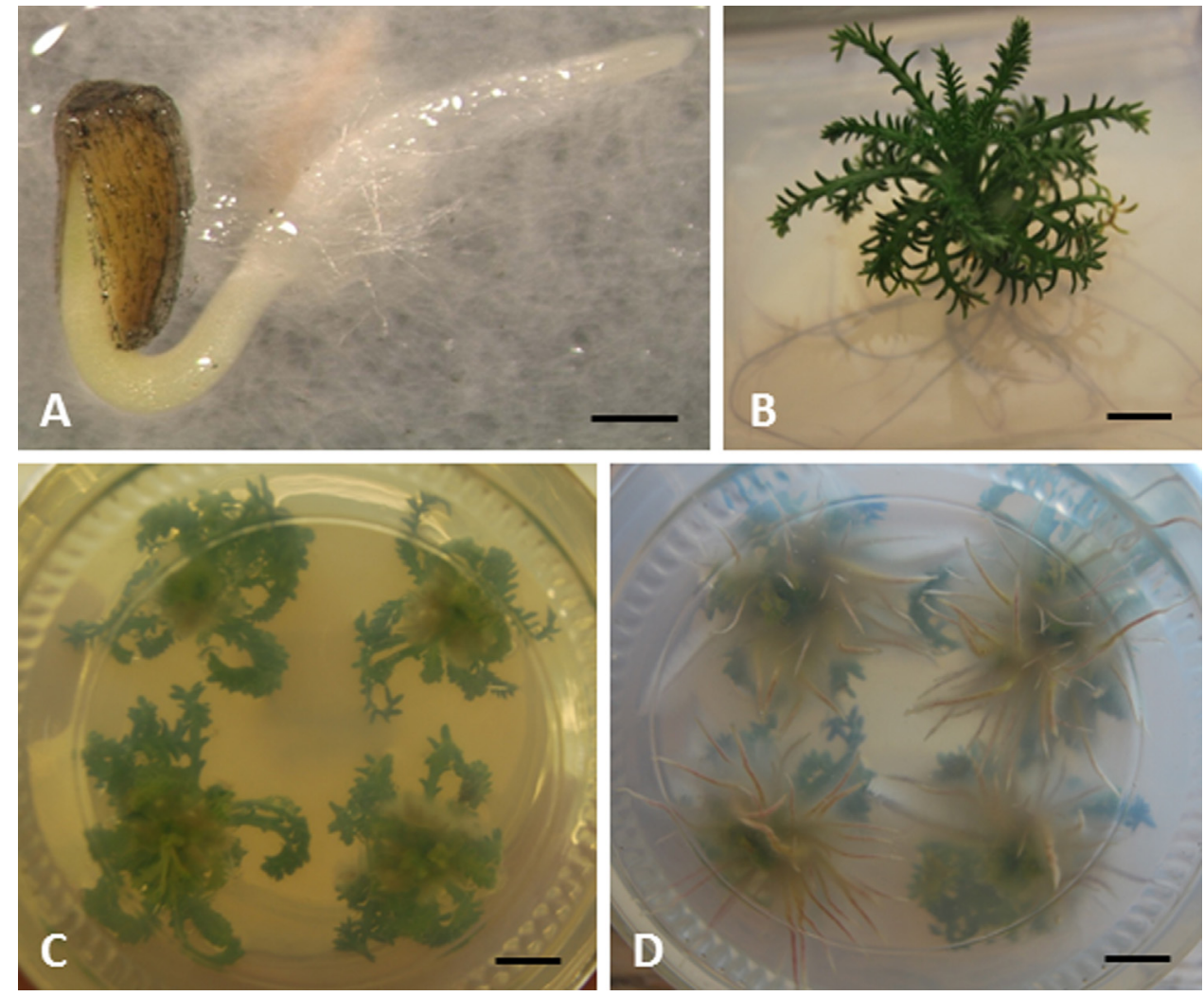

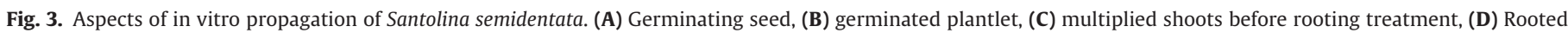
shoots after treatment with IBA. Scale bars correspond to $1 \mathrm{~mm}$ in A and to $10 \mathrm{~mm}$ in $\mathrm{B}, \mathrm{C}$ and D.

Inc., Copyright ${ }^{\odot}$ 2004, Erkrath, Germany) and Statistica 10.0 package (StatSoft Inc.).

\section{Results and discussion}

Among the Plant kingdom, only about $10 \%$ of the existing higher plant species have been chemically characterized (Yuliana et al., 2011). Such fact highlights the unknown diversity that exists, representing an immense reservoir of molecules with biotechnology and/or medicinal potential that species not yet characterized may hold. Here we report, for the first time, the potential of S. semidentata as antioxidant, neuroprotective, AChE inhibitor and antifungal.

Total phenolic quantification of hydroethanolic extracts (Table 1 ) reveals the potential of this plant species to have chemical scavengers of free radicals. The total flavonoid content was also determined since flavonoids are a class of (poly) phenols strongly associated with antioxidant capacity (Table 1 ).

The $S$. semidentanta extract ability to scavenge peroxyl (ROO•), one of the most important free radicals for the human body, was also measured by the oxygen radical absorbance capacity (ORAC) method (Table 1). The antioxidant potential of other plants of the genus Santolina had already been described. Nikolova et al. (2011) have evaluated Santolina rosmarinifolia L. (herba) and Tavares et al. (2011) evaluated Santolina impressa. Although not directly comparable, $S$. rosmarinifolia presented a significant free radical scavenging activity among 57 extractsof 54 plant species of 30 families (Nikolova et al., 2011). Interestingly, S. semidentata presents higher content in phenolics and flavonoids comparing with $S$. impressa, also a Portuguese endemic plant from the Comporta/Galé site, in Southwestern Portugal (Tavares et al., 2011) (namely $23.16 \pm 0.49$ vs. $4.36 \pm 0.32 \mathrm{mg} \mathrm{GAE} \mathrm{g}^{-1} \mathrm{dw}$, and $11.86 \pm 0.12$ vs. $\left.1.13 \pm 0.07 \mathrm{mg} \mathrm{CE} \mathrm{g}^{-1} \mathrm{dw}\right)$. S. impressa presented a lower level of these phytochemical that reflects in a much lower antioxidant capacity for peroxyl radical than $S$. semidentata, here characterized for the first time.

Studies with other Asteraceae family members (Fabri et al., 2011; Shahwar et al., 2011) have also shown antioxidant properties, highlighting the importance of studying this unexplored and uncharacterized Iberian endemism.

With the main goal of obtaining a (poly) phenol-enriched fraction (PEF), a fractionation by solid phase extraction was performed (Tavares et al., 2010a,b). This method allows the elimination of some of the compounds of the total extract, as well as the organic acids and sugars that may interfere with the studied bioactivities (Ross et al., 2007; Tavares et al., 2010a,b). A total phenol content measurement of $S$. semidentata $\mathrm{PEF}$ was performed, having revealed a greater value in total phenols than the simple hydroethanolic extract (Table 1). Such results may suggest that, with the fractionation by solid phase extraction, some compounds of the total extract interfering with phenols quantification have been eliminated, leading to a phenol recovery percentage greater than $100 \%$ (data not shown).

\subsection{PEF composition}

High performance liquid chromatography with diode array detection (HPLC-DAD) was then used for profiling the compounds of leaf extracts. The resulting phytochemical profile (Fig. 1) identified some of the major compounds by analysing their UV spectra and comparison with standards, such as those proposed by Robards and Antolovich (1997) for classes of flavonoids (Robards and Antolovich, 1997). Flavones typically show maximum absorption rates in an intense Band II (310-350 nm) with a shoulder or low intensity Band I (250-280 nm). Flavonols absorb at $250-280 \mathrm{~nm}$ (Band II) and 350-385 nm (Band I), while hydroxycinnamic acids 
Table 2

Composition of Santolina semidentata essential oil.

\begin{tabular}{|c|c|c|c|}
\hline $\mathrm{IR}^{\mathrm{a}}$ & $\mathrm{IR}^{\mathrm{b}}$ & Compound & $\%$ \\
\hline 923 & 1030 & $\alpha$-Thujene & 0.3 \\
\hline 930 & 1030 & $\alpha$-Pinene & 26.7 \\
\hline 943 & 1076 & Camphene & 0.4 \\
\hline 946 & 1131 & Verbenene & 0.6 \\
\hline 964 & 1127 & Sabinene & 2.0 \\
\hline 969 & 1118 & $\beta$-Pinene & 6.6 \\
\hline 981 & 1162 & Myrcene & 0.5 \\
\hline 997 & n.d. & $\alpha$-Phellandrene & 0.1 \\
\hline 1009 & 1186 & $\alpha$-Terpinene & 0.8 \\
\hline 1012 & 1276 & p-Cymene & 1.2 \\
\hline 1019 & 1206 & Limonene & 1.6 \\
\hline 1020 & 1215 & $\beta$-Phellandrene & 0.4 \\
\hline 1020 & 1215 & 1,8-Cineole & 2.2 \\
\hline 1025 & 1234 & Z- $\beta$-Ocimene & 0.2 \\
\hline 1036 & 1252 & E- $\beta$-Ocimene & 0.2 \\
\hline 1047 & 1249 & $\delta$-Terpinene & 1.4 \\
\hline 1068 & 1442 & Cymenene & 0.7 \\
\hline 1077 & 1288 & Terpinolene & 0.4 \\
\hline 1086 & n.d. & Hotrienol & 1.0 \\
\hline 1104 & 1490 & $\alpha$-Campholenal & 1.6 \\
\hline 1107 & 1551 & Z-p-2-Menthen-1-ol & 0.5 \\
\hline 1118 & 1515 & Camphor & 0.4 \\
\hline 1121 & 1648 & E-Pinocarveol & 11.2 \\
\hline 1126 & n.d. & Sabina ketone & 0.9 \\
\hline 1128 & 1670 & E-Verbenol & 1.1 \\
\hline 1135 & 1566 & Pinocarvone & 5.9 \\
\hline 1144 & 1726 & p-Menth-1,5-dien-8-ol & 1.1 \\
\hline 1146 & 1544 & iso-Pinocamphone & 3.1 \\
\hline 1158 & 1596 & Terpinene-4-ol & 3.7 \\
\hline 1166 & 1624 & Myrtenal & 2.0 \\
\hline 1171 & 1689 & $\alpha$-Terpineol & 0.7 \\
\hline 1176 & 1788 & Myrtenol & 1.0 \\
\hline 1177 & 1701 & Verbenone & 3.6 \\
\hline 1198 & 1829 & E-Carveol & 0.8 \\
\hline 1212 & 1777 & Cuminaldehyde & 0.4 \\
\hline 1368 & 1490 & $\alpha$-Copaene & 0.3 \\
\hline 1445 & 1639 & allo-Aromadendrene & 1.2 \\
\hline 1464 & 1701 & Germacrene D & 0.5 \\
\hline 1551 & 2114 & Spathulenol & 0.7 \\
\hline 1555 & 1974 & Caryophyllene oxide & 0.6 \\
\hline 1579 & 1788 & Oplopenone & 0.4 \\
\hline 1580 & 2019 & Ledol & 0.5 \\
\hline \multirow[t]{6}{*}{1616} & 2169 & T-Muurolol & $t$ \\
\hline & & Monoterpene hydrocarbons & 46.3 \\
\hline & & Oxygen containing monoterpenes & 39 \\
\hline & & Sesquiterpene hydrocarbons & 2 \\
\hline & & Oxygen containing sesquiterpenes & 2.2 \\
\hline & & Total identified & 89.5 \\
\hline
\end{tabular}

Compounds listed in order to their elution on the SPB-1 column.

n.d. $=$ not determined.

$t=\operatorname{traces}(\leq 0.05 \%)$

a Retention indices on the SPB-1 column relative to C8-C23 n-alkanes.

b Retention indices on the SupelcoWax-10 column relative to C8-C23n-alkanes.

demonstrate no Band I and absorb at 227-245 $\mathrm{nm}$ and at 310-332 (Band II).

The HPLC analysis of the PEF showed the presence of 8 principal peaks (Fig. 1), revealing the complexity of the analyzed sample. Of the considered peaks registered from the chromatographic profile at $280 \mathrm{~nm}$, hydroxicinammic acids derivatives (peaks 3, 7 and 8), flavones (peak 4 and 6), simple phenolic acids (peak 1), flavonol (peak 5) and coumarin (peak 2) were detected. In accordance with these results, also ferulic acid and its derivatives were the principal components identified in S. impressa hydroethanolic extracts by HPLC-DAD (Tavares et al., 2011).

\subsection{Essential oil composition}

The essential oil was obtained in yield of $1.0 \%(\mathrm{v} / \mathrm{w})$. The compounds identified and their percentages are listed by order of their elution on a polydimethylsiloxane column (Table 2). The oil is characterized by high contents of monoterpenic hydrocarbons (46.3\%) and oxygen-containing monoterpenes (39.0\%). The main constituents of the oils were $\alpha$-pinene (26.7\%), E-pinocarveol (11.2\%), and pinocarvone (5.9\%). This composition is markedly different from the oil obtained from $S$. semidentata from Spain, which is characterized by high content of sesquiterpenes (Alonso and Negueruela, 1998).

\subsection{Bioactivities}

\subsubsection{AChE inhibitory activity}

Few AChE inhibitors have yet been approved for AD therapy (Bachurin, 2003) and pharma products present adverse side effects; therefore, finding natural sources of compounds exhibiting AChE inhibitory effects is crucial and must be pursuit. Santolina genus has been reported as an important source of compounds with potential biotechnology applications due to their associated bioactivities (Fabri et al., 2011; Silván et al., 1996; Tavares et al., 2011). In order to evaluate the AChE inhibitory potential for compounds of $S$. semidentata, hydroethanolic extracts and PEF were studied. A SPE fractionation was performed to S. semidentata hydroethanolic extract, where fraction corresponds to sugars and organic acids was discharged and obtained a (poly)phenolenriched fraction (PEF) (Tavares et al., 2011). Obtained results for AChE inhibition revealed that $S$. semidentata PEF present a potent AChE inhibition capacity. Other members from Asteraceae family (Bidensbiternata, Seneciomacrophylla and S. impressa) have also revealed AChE inhibitory properties (Shahwar et al., 2011; Tavares et al., 2011). Comparing the effect of $2 \mathrm{mg} \mathrm{mL}^{-1}$ of extract from $S$. impressa with the same quantity of extract from S. semidentanta, the later present definitely stronger inhibition properties ( $40.71 \%$ vs. $64.26 \%$, respectively). This lead us to calculate the IC50 $\left(\mu \mathrm{g} \mathrm{mL}^{-1}\right)$ for the hydroethanolic extract and also to fractionate the extract to obtain a (poly)phenol enriched fraction (PEF). There is no considerable difference in the IC50 between hydroethanolic extracts and the PEF fraction (namely, $923.44 \pm 153.34 \mu \mathrm{g} \mathrm{mL}^{-1} \mathrm{vs}$ $.1112 .87 \pm 268.41 \mu \mathrm{g} \mathrm{mL}^{-1}$ ) suggesting that the main compounds present in the extract responsable for the AChE inhibitory activity can be related with the compounds present in PEF.

\subsubsection{Cytotoxicity profile and neuroprotective potential}

Evaluation of $S$. semidentata PEF neuroprotective potential was performed taking into account the greater AChE inhibitory capacity comparatively to other species and versus the hydroethanolic extract. Based on this, $S$. semidentata PEF revealed to be a more promising source of biomolecules with potential neuroprotective capacity and therefore it was tested for this bioactivity in a human neurodegeneration cell model.

Nontoxic ranges of the extract were defined using a neuroblastoma cell line for a range of $0-200 \mu \mathrm{g} \mathrm{GAE} \mathrm{mL}^{-1}$ for $24 \mathrm{~h}$ (Gomes et al., 2013; Tavares et al., 2012a,b). To cause a complete cell death, a concentration of $100 \mu \mathrm{g} \mathrm{GAE} \mathrm{mL}{ }^{-1}$ S. semidentata PEF is required (Fig. 2A). A concentration of approximately $40 \mu \mathrm{g} \mathrm{GAE} \mathrm{mL}^{-1}$ S. semidentata PEF was required to attain $50 \%$ of cell viability. Although not explored in this work, this cytotoxicity profile reveal some interference of S. semidentata phenols in the cell growth at relatively low levels which suggest further studies to ascertain their anti-cancer potential by comparing this effect in other cancer cells in parallel with normal cells.

After determining the range of nontoxic concentrations, four concentrations of $S$. semidentata PEF were selected and tested in a neurodegeneration cell model to assess their cytoprotective effects. This model consists of neuroblastoma cells injured with $300 \mu \mathrm{M}$ $\mathrm{H}_{2} \mathrm{O}_{2}$ for $24 \mathrm{~h}$, a condition that reduces cell viability for $50 \%$ in SK-N-MC cells (Tavares et al., 2012a,b). Cell viability was assessed using the CellTiter-Blue ${ }^{\circledR}$ Cell Viability Assay (Promega), a colori- 
Table 3

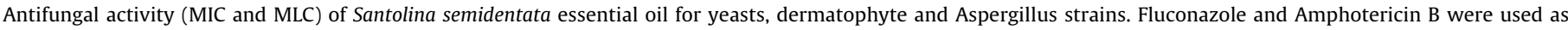
controls. Results were obtained from 3 independent experiments performed in duplicate.

\begin{tabular}{|c|c|c|c|c|c|c|}
\hline \multirow[t]{2}{*}{ Strains } & \multicolumn{2}{|c|}{ Essential oil } & \multicolumn{2}{|c|}{ Fluconazole } & \multicolumn{2}{|c|}{ Amphotericin B } \\
\hline & $\mathrm{MIC}^{\mathrm{a}}$ & $\mathrm{MLC}^{\mathrm{a}}$ & $\mathrm{MIC}^{\mathrm{b}}$ & $\mathrm{MLC}^{\mathrm{b}}$ & $\mathrm{MIC}^{\mathrm{b}}$ & MLC $^{b}$ \\
\hline Candida albicans ATCC 10231 & 1.25 & 1.25 & 1 & $>128$ & N.T & N.T \\
\hline Candida tropicalis ATCC 13803 & 1.25 & $1.25-2.5$ & 4 & $>128$ & N.T & N.T \\
\hline Candida krusei H9 & 0.64 & 1.25 & 64 & $64-128$ & N.T & N.T \\
\hline Candida guillermondii MAT23 & 0.64 & 1.25 & 8 & 8 & N.T & N.T \\
\hline Candida parapsilosis ATCC 90018 & 1.25 & 2.5 & $<1$ & $<1$ & N.T & N.T \\
\hline Cryptococcus neoformans CECT 1078 & 0.32 & 0.64 & 16 & 128 & N.T & N.T \\
\hline Trichophyton mentagrophytes FF7 & 0.32 & 0.32 & $16-32$ & $32-64$ & N.T & N.T \\
\hline Microsporum canis FF1 & 0.32 & 0.32 & 128 & 128 & N.T & N.T \\
\hline Trichophyton rubrum CECT 2794 & 0.16 & 0.32 & 16 & 64 & N.T & N.T \\
\hline M. gypseum CECT 2908 & 0.32 & 0.32 & 128 & $>128$ & N.T & N.T \\
\hline Epidermophyton floccosum FF9 & 0.16 & 0.16 & 16 & 16 & N.T & N.T \\
\hline T. mentagrophytes var. interdigitale CECT 2958 & 0.32 & 0.32 & 128 & $\geq 128$ & N.T & N.T \\
\hline T. verrucosum CECT 2992 & 0.32 & 0.64 & $>128$ & $>128$ & N.T & N.T \\
\hline Aspergillus niger ATCC16404 & 1.25 & 10 & N.T & N.T & $1-2$ & 4 \\
\hline A. fumigatus ATCC 46645 & 0.64 & 5.0 & N.T & N.T & 2 & 4 \\
\hline A. flavus F44 & 2.5 & 10 & N.T & N.T & 2 & 8 \\
\hline
\end{tabular}

N.T - not tested.

a MIC and MLC were determined by a macrodilution method and expressed in $\mu \mathrm{L} \mathrm{mL}^{-1}(\mathrm{~V} / \mathrm{V})$.

b MIC and MLC were determined by a macrodilution method and expressed in $\mu \mathrm{gL}^{-1}(\mathrm{~W} / \mathrm{V})$.

metric method to determine the number of viable cells in culture. The results show (Fig. 2B) that under $\mathrm{H}_{2} \mathrm{O}_{2}$ stress, levels between 3 to $6 \mathrm{GAE} \mathrm{mL}^{-1}$ of $S$. semidentata PEF are effective in promotion a protective effect and we seem to have a dose dependent response

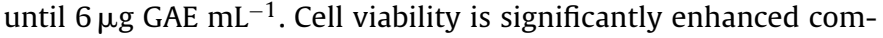
pared with cells only treated with $\mathrm{H}_{2} \mathrm{O}_{2}$. These results reinforce the potential of $S$. semidentata PEF for the use in neuroprotection together with the antioxidant and $\mathrm{AChE}$ inhibitory properties.

\subsubsection{Antifungal activity}

Evaluation of MIC and MLC of S. semidentata oil showed a variation of inhibition among all the fungal tested. The results of the antifungal activity are summarized in Table 3. The majority of dermatophyte strains showed more sensitivity to this oil when compared with Candida and Aspergillus strains, particularly for Epidermophytonfloccosum and Trichophyton rubrum, with MIC and MLC values of 0.16 and $0.32 \mu \mathrm{L} \mathrm{mL}^{-1}$, respectively. For dermatophyte strains, in most cases, the MIC was equivalent to the MLC, indicating fungicidal activity of this oil. Among the tested yeasts, Cryptococcus neoformans was the strain that showed more sensibility with MIC of $0.32 \mu \mathrm{L} \mathrm{mL}^{-1}$. This oil might be useful for therapheutical purposes, particularly in the treatment of dermatophytosis. This infection has increased over the past few decades, particularly among immunocompromised hosts (Zuzarte et al., 2011). Other members of the Asteraceae family, such as, Otanthusmaritimus, have also demonstrated important antidermatophitic activity (Cabral et al., 2013).

\subsection{Seed conservation and in vitro propagation}

Two hundred S. semidentata seeds collected in the field were stored at the Seed Bank A.L. Belo Correia, Museu Nacional de História Natural e da Ciência, and atthe Seed Bank Prof. João do Amaral Franco, JardimBotânico da Ajuda - Instituto Superior de Agronomia for ex situ conservation. Seeds were stored according to international standards for long-term seed conservation (ENSCONET, 2009; FAO/IPGRI, 1994) at the Belo Correia Seed Bank, and germination requirements were studied in order to test viability of banked seeds in the future. Germination percentage of S. semidentata seeds varied between $76 \%$ and $86 \%$ (Table 4 ). Incubation temperature had no significant effect on final germination percentage (ANOVA, $F=0,712 ; p=0,563$ ). Similarly to other Santolina species (Rivero-Guerra, 2008), the results indicate that $S$.
Table 4

Germination percentage of Santolina semidentata incubated at $15^{\circ} \mathrm{C}, 20^{\circ} \mathrm{C}$ and $25^{\circ} \mathrm{C}$ constant temperatures and an alternate temperature, $20 / 10^{\circ} \mathrm{C}$ (day/night). The values correspond to the mean of at least four independent measurements \pm standard deviation.

\begin{tabular}{ll}
\hline Temperature & Germination\% \\
\hline $15^{\circ} \mathrm{C}$ & $85.71 \pm 4.28$ \\
$20^{\circ} \mathrm{C}$ & $75.63 \pm 10.85$ \\
$25^{\circ} \mathrm{C}$ & $79.45 \pm 6.61$ \\
$20 / 10^{\circ} \mathrm{C}$ & $79.58 \pm 14.50$ \\
\hline
\end{tabular}

semidentata does not exhibit seed dormancy and optimal germination temperatures range between 15 and $20^{\circ} \mathrm{C}$, a typical strategy of Mediterranean species (Thanos et al., 1995).

A protocol for in vitro propagation of $S$. semidentata was here established in order to test the possibility of including vegetative propagation of plants collected in the wild within a strategic conservation plan to ensure a sustainable production of plants towards biotechnology exploitation.Vegetative propagation starting from in vitro germinated seeds offers advantages relatively to collecting and disinfecting young shoots from wild plants. In seeds the embryo is protected by several external layers, allowing the use of stringent desinfection procedures. While in vitro germination of $S$. semidentata seeds was not affected by temperature (data not shown), the disinfection procedure was critical for obtaining decontaminated seeds able to germinate. The immersion in a $3 \%(\mathrm{v} / \mathrm{v}) \mathrm{NaClO}$ solution for $10 \mathrm{~min}$ was the most effective disinfecting treatment for S. semidentata seeds and germination rates of approximately $35 \%$ were obtained after this procedure. However, the same concentration of disinfecting agent applied for a longer period (20 min) was too aggressive and germination rates dropped to approximately $6 \%$.

Multiplication of apical shoots removed from seedlings was attempted on medium without supplementation of growth regulators since these compounds have been often associated to hyperhydricity of the shoots or stunted growth (Kataeva et al., 1991). In these conditions we were able to successfully multiply the shoots and these showed a normal appearance (Fig. 3). According to the evaluation performed every 21 days after each subculture, a reduction of the multiplication rate from 4 to 1.7 was observed from the first to the second subculture. However, this rate increased again in the third subculture to the initial value (approx. 4) and was kept stable after the fourth subculture. Furthermore, the obtained 
shoots elongated as expected and did not exhibit any signs of vitrification (Fig. 3B).

Rooting of the obtained shoots was only successful when using a high concentration of IBA $\left(183 \mathrm{mg} \mathrm{L}^{-1}\right)$ for $16 \mathrm{~h}$, as described previously by (Tereso et al., 2008), allowing to achieve a rooting efficiency of $100 \%$ (Fig. 3C and D). Similarly, Casado et al. (2002) have reported that for $S$. canescens, rooting was highest when shoots were placed onto media containing auxins alone, and IBA-induced roots were more fibrous than roots induced by other auxins such as 1-naphthaleneacetic acid (NAA) or indole-3-acetic acid (IAA). We obtained a median number of 21 roots per plantelet, while the main root had approximately $2 \mathrm{~cm}$. At the end of the rooting period, the acclimatization success of the plants was variable but always under $30 \%$ due to over growth of fungi and thus the use of fungicides may be needed for increasing the success of this step. These results demonstrate that in vitro propagation of $S$. semidentata is feasible and the conditions here provided allowed to achieve satisfactory rates of shoot multiplication, showing promising potential for future biotechnological exploitation.

\section{Conclusions}

Neurodegenerative diseases are multifactorial disorders in which many biological processes become unregulated. A multitarget therapeutic strategy aiming at different pharmacological mechanisms might provide a more rational and improved dementia treatment approach. S. semidentata (poly) phenol enriched fraction revealed to be a potential source of neuroprotective natural products. Due to its antioxidant capacity, AChE inhibitory properties and neuroprotective effect in a human cell model for neurodegeneration, this plant is considered a promising source of neuroprotective phytomolecules, either as alternative neuroprotective drugs or as leads for synthesizing more effective molecules. The extracts, therefore, deserve to be the target of bioguided fractionation and further characterization. The wide-spectrum antifungal activity and high potency of the oil of S. semidentata support further investigations into the development of this essential oil for clinical use in the management of superficial and/or mucosal fungal infections. To ensure the sustainable use of this plant, an optimal seed germination range temperature was defined and also a micropropagation procedure was established, yet the stable production in vitro of the identified secondary metabolites needs to be confirmed although it is expected that in vitro propagated plants maintain that stability as already verified for other Santolina species.

\section{Acknowledgements}

The authors wish to thank to "Fundo EDP para a Biodiversidade" for financial support. This work was also supported by "Fundação para a Ciência e a Tecnologia" through grant PEst-OE/EQB/LA0004/2011, BGCT/33418/2008, Green-it: UID/Multi/04551/2013, iNOVA4Health: UID/Multi/04462/2013 and financial support to CNS (IF/01097/20132), RP (SFRH/BD/63615/2009), IF (SFRH/BD/86584/2012) and AG (SFRH/BD/103155/2014).

\section{References}

Adams, R.P., 1995. Identification of essential oil components by gas chromatography/mass spectrometry. In: Adams, R.P. (Ed.), Identification of Essential Oil Components by Gas Chromatography/mass Spectrometry. Allured Publishing Corporation, Carol Stream, USA

Alonso, M.J., Negueruela, V., 1998. The essential oils of four Santolina species. Flavour Fragance J. 3, 37-42.

Ardestani, A., Yazdanparast, R., 2007. Antioxidant and free radical scavenging potential of Achillea santolina extracts. Food Chem. 104, 21-29.

Bachurin, S.O., 2003. Medicinal chemistry approaches for the treatment and prevention of Alzheimer's disease. Med. Res. Rev. 23, 48-88.
Cabral, C., Cavaleiro, C., Gonçalves, M.J., Cruz, M.T., Lopes, M.C., Salgueiro, L., 2013. Otanthus maritimus (L.) Hoffmanns. \& Link as a source of a bioactive and fragrant oil. Ind. Crops Prod. 43, 484-489.

Casado, J.P., Navarro, M.C., Utrilla, M.P., Martínez, A., Jiménez, J., 2002. Micropropagation of Santolina canescens Lagasca and in vitro volatiles production by shoot explants. Plant Cell Tissue Org. Cult. 69, 147-153.

Cavaleiro, C., Salgueiro, L.R., Miguel, M.G., Proença da Cunha, A., 2004. Analysis by gas chromatography-mass spectrometry of the volatile components of Teucrium lusitanicum and Teucrium algarbiensis. J. Chromatogr. A 1033, $187-190$.

CEC (2009) Commission of the European Communities. Composite Report on the Conservation Status of Habitat Types and Species as required under Article 17 of the Habitats Directive. Report from the Commission to the Council and the European Parliament. In, Brussels.

CLSI-Clinical and Laboratory Standards Institute, 2008. Reference Method for Broth Dilution Antifungal Susceptibility Testing of Yeasts. Approved Standard, third ed., M27-A3, Wayne, PA.

CLSI-Clinical and Laboratory Standards Institute, 2008 Reference Method for Broth Dilution Antifungal Susceptibility Testing of Filamentous Fungi. Approved Standard, third ed., M38-A2, Wayne, PA.

Council of Europe, 1997. European Pharmacopoeia, 3rd ed. Council of Europe, Strasbourg.

De Logu, A., Loy, G., Pellerano, M.L., Bonsignore, L., Schivo, M.L., 2000. Inactivation of HSV-1 and HSV-2 and prevention of cell-to-cell virus spread by Santolina insularis essential oil. Antiviral Res. 48, 177-185.

Ellman, G.L., Courtney, K.D., Andres, V.J., Feather-Stone, R.M., 1961. A new and rapid colorimetric determination of acetylcholinesterase activity. Biochem. Pharmacol. 7, 88-95.

ENSCONET, 2009. In: Royal Botanic Gardens, K. (Ed.), ENSCONET Curation Protocols \& Recommendations. Royal Botanic Gardens, Kew.

Fabri, R.L., Nogueira, M.S., Dutra, L.B., Bouzada, M.L., Scio, E., 2011. Antioxidant and antimicrobial potential of Asteraceae species. Rev. Bras. plantas Med. 13 183-189.

FAO/IPGRI, 1994. In: Food and Agriculture Organization of the United Nations (Ed.) Genebank Standards. International Plant Genetic Resources Institute, Rome.

Ferrari, B., Tomi, F., Casanova, J., 2005. Terpenes and cetylene derivatives from the roots of Santolina corsica (Asteraceae). Biochem. Syst. Ecol. 33, 445-449.

Fortalezas, S., Tavares, L., Pimpão, R., Tyagi, M., Pontes, V., Alves, P., McDougall, G., Stewart, D., Ferreira, R., Santos, C., 2010. Antioxidant properties and neuroprotective capacity of strawberry tree fruit (Arbutus unedo). Nutrients 2 , 214-229.

Gomes, A., Fortalezas, S., Pimpão, R., Figueira, I., Maroco, J., Aguiar, C., Ferreira, R. Miguel, C., Santos, C., 2013. Valuing the endangered species Antirrhinum lopesianum: neuroprotective activities and strategies for in vitro plant propagation. Antioxidants 2, 273-292.

ICN, 2006. Fichas de caracterização ecológica e de gestão. Plano Sectorial da Rede Natura 2000

Iglesias, I., Feijóo, M.C., Ortiz, S., 2000. Contribution to the conservation studies of Santolina melidensis (Rodr. -Oubióña \& S. Ortiz) Rodr. -Oubióa \& S. Ortiz. Portugaliae Acta Biol. 19, 107-112.

Joulain, D., König, W.A., 1998. The atlas of spectral data of sesquiterpene hydrocarbons. Hamburg.

Kataeva, N.V. Alexandrova, I.G., Butenko, R.G., Dragavtceva, E.V. 1991. Effect of applied and internal hormones on vitrification and apical necrosis of different plants cultured in vitro. Plant Cell Tissue Org. Cult. 27, 149-154.

Murashige, T., Skoog, F., 1962. A revised medium for rapid growth and bioassays with Tobacco tissue cultures. Physiol. Plant 15 (3), 473-497.

Naqash, S.Y., Nazeer, R.A., 2011. Anticoagulant, antiherpetic and antibacterial activities of sulphated polysaccharide from Indian Medicinal Plant Tridax procumbens L. (Asteraceae). Appl. Biochem. Biotechnol. 165, 902-912.

Nikolova, M., Evstatieva, L., Nguyen, T.D., 2011. Screening of plant extracts for antioxidant properties. Bot. Serb. 35, 43-48.

Rivero-Guerra, A.O., 2008. Phenotypic differentiation of peripheral populations of Santolina rosmarinifolia (Asteraceae). Bot. J. Linn. Soc. 158, 650-668.

Rivero-Guerra, A.O., 2009. Cytogenetics, geographical distribution, pollen stainability and fecundity of five diploid taxa of Santolina rosmarinifolia L. aggregate (Asteraceae: Anthemideae). Plant Syst. Evol. 281, 17-34.

Robards, K., Antolovich, M., 1997. Analytical chemistry of fruit bioflavonoids - A review. Analyst 122,11R-34R.

Ross, H.A., McDougall, G.J., Stewart, D., 2007. Antiproliferative activity is predominantly associated with ellagitannins in raspberry extracts. Phytochemistry 68, 218-228.

Sacchetti, G., Romagnoli, C., Ballero, M., Tosi, B., Poli, F., 1997. Internal secretory structures and preliminary phytochemical investigation on flavonoid and coumarin content in Santolina insularis (Asteraceae). Phyton 37, 219-228

Shahwar, D., Ullah, S., Raza, M.A., Sana, U., Yasmeen, A., Ghafoor, S., Ahmad, N., 2011. Acetylcholine esterase and antioxidant potential of some members of Asteraceae and Euphorbiaceae. J. Med. Plants Res. 5, 7011-7016.

Silván, A.M., Abad, M.J., Bermejo, P., Sollhuber, M., Villar, A., 1996. Antiinflammatory activity of coumarins from Santolina oblongifolia. J. Nat. Prod. 59, 1183-1185.

Tavares, L., Carrilho, D., Tyagi, M., Barata, D., Serra, A.T., Duarte, C.M.M., Duarte, R.O., Feliciano, R.P., Bronze, M.R., Chicau, P., Espírito-Santo, M.D., Ferreira, R.B., Dos Santos, C.N., 2010a. Antioxidant capacity of macaronesian traditional medicinal plants. Molecules 15, 2576-2592. 
Tavares, L., Figueira, I., Macedo, D., McDougall, G.J., Leitão, M.C., Vieira, H.L.A., Stewart, D., Alves, P.M., Ferreira, R.B., Santos, C.N., 2012a. Neuroprotective effect of blackberry (Rubus sp.) polyphenols is potentiated after simulated gastrointestinal digestion. Food Chem. 131, 1443-1452.

Tavares, L., Fortalezas, S., Carrilho, C., McDougall, G.J., Stewart, D., Ferreira, R.B., Santos, C.N., 2010b. Antioxidant and antiproliferative properties of strawberry tree tissues. J. Berry Res. 1, 3-12.

Tavares, L., Fortalezas, S., Tyagi, M., Barata, D., Serra, A., Duarte, C., Duarte, R. Feliciano, R., Bronze, M., Espírito-Santo, M., Ferreira, R., Santos, C., 2011. Bioactive compounds from endemic plants of Southwest Portugal: inhibition of acetylcholinesterase and radical scavenging activities. Pharma Biol. 50, 239-246.

Tavares, L., McDougall, G.J., Fortalezas, S., Stewart, D., Ferreira, R.B., Santos, C.N., $2012 \mathrm{~b}$. The neuroprotective potential of phenolic-enriched fractions from four Juniperus species found in Portugal. Food Chem. 135, 562-570.

Tereso, S., Miguel, C., Mascarenhas, M., Roque, A., Trindade, H., Maroco, J., Oliveira, M., 2008. Improved in vitro rooting of Prunus dulcis Mill. cultivars. Biol. Plant. $52,437-444$.
Thanos, C.A., Kadis, C.C., Skarou, F., 1995. Ecophysiology of germination in the aromatic plants thyme, savory and oregano (Labiatae). Seed Sci. Res. 5, 161-170.

Utrilla, M.P., Navarro, M.C., Jiménez, J., Montilla, M.P., 1995. Santolindiacetylene, a new polyacetylene derivative isolated from the essential oil of Santolina canescens. J. Nat. Prod. 58, 1749-1752.

Vale-Silva, L.A., Gonçalves, M.J., Cavaleiro, C., Salgueiro, L., Pinto, E., 2010. Antifungal activity of the essential Oil of thymus $\mathrm{x}$ viciosoi against Candida Cryptococcus, Aspergillus and Dermatophyte Species. Planta Med. 76, 882-888.

Yuliana, N.D., Khatib, A., Choi, Y.H., Verpoorte, R., 2011. Metabolomics for bioactivity assessment of natural products. Phytother. Res. 25, 157-169.

Zuzarte, M., Gonçalves, M.J., Canhoto, J.M., Salgueiro, L., 2011. Antidermatophytic activity of essential oils. in: science against microbial pathogens: communicating current research and technological advances. In: In: Méndez-Vilas, A. (Ed.), Microbiology Book Series, n`3, vol. 2. Formatex Research Center, Badajoz (Spain), pp. 1167-1178. 